\title{
The aggregation-sex pheromones of the cerambycid beetles Anaglyptus mysticus and Xylotrechus antilope ssp. antilope: new model species for insect conservation through pheromone-based monitoring
}

\author{
Mikael A. Molander ${ }^{1}$ D $\cdot$ Björn Eriksson ${ }^{1}$ (D) $\cdot$ Inis B. Winde ${ }^{1} \cdot$ Yunfan Zou $^{2} \cdot$ Jocelyn G. Millar $^{2}$ (D) Mattias C. Larsson ${ }^{1}$ (D)
}

Received: 7 December 2018 / Accepted: 30 March 2019 / Published online: 9 April 2019

(c) The Author(s) 2019

\begin{abstract}
We studied the pheromone chemistry of the cerambycids Anaglyptus mysticus and Xylotrechus antilope ssp. antilope with the goal of identifying attractants that could be used as tools for pheromone-based monitoring of these two species, which are rare and red-listed in parts of northern Europe. Beetles were reared from naturally colonized branches of hazel (Corylus avellana) or oak (Quercus robur), respectively, and used for headspace sampling. The extracts of volatiles were analyzed by gas chromatography-mass spectrometry. Males of A. mysticus consistently produced large quantities of $(R)$-3-hydroxy2-hexanone and 2-nonanone, minor amounts of 2,3-hexanedione, and trace amounts of six other compounds. The average proportion of 2-nonanone to $(R)$-3-hydroxy-2-hexanone was 70:100. Males of $X$. antilope produced large quantities of $(S)$ 2-hydroxy-3-octanone, and minor quantities of 2,3-octanedione. None of these compounds were present in the corresponding extracts of females from either species. The attractiveness of the dominant compounds produced by each species was determined in field bioassays. Lures with racemic 3-hydroxy-2-hexanone and 2-nonanone as single compounds were not attractive to A. mysticus. However, the compounds acted synergistically in blends of 100:100 and 160:100 of 2-nonanone to the hydroxyketone's $(R)$-enantiomer, but not in a 40:100 blend. Similarly $(S)$-2-hydroxy-3-octanone and its racemate attracted significantly more $X$. antilope than controls. Males and females of both species were captured in approximately equal numbers. The aggregation-sex pheromones of A. mysticus and X.antilope have high potential to serve as sensitive and efficient tools for detection and monitoring of local populations, and in studies of the species' ecology and conservation requirements.
\end{abstract}

Keywords Cerambycidae $\cdot(R)$-3-Hydroxy-2-hexanone $\cdot$ 2-Nonanone $\cdot(S)$-2-Hydroxy-3-octanone $\cdot$ Semiochemical Monitoring

Communicated by Günther Raspotnig.

Electronic supplementary material The online version of this article (https://doi.org/10.1007/s00049-019-00281-5) contains supplementary material, which is available to authorized users.

Mikael A. Molander

mikael.molander@slu.se

1 Unit of Chemical Ecology, Department of Plant Protection Biology, Swedish University of Agricultural Sciences, Sundsvägen 14, Box 102, 23053 Alnarp, Sweden

2 Departments of Entomology and Chemistry, University of California, Riverside, CA, USA

\section{Introduction}

The benefits of exploiting pheromones to detect and monitor a wide variety of pest insect species have long been recognized (Baker and Heath 2005; Witzgall et al. 2010), but pheromones have rarely been used for monitoring and study of rare species of conservation concern (Larsson et al. 2009; Tolasch et al. 2013; Oleander et al. 2015; Larsson 2016; Leal 2017). However, over the past decade, several studies have shown that pheromone-based sampling can be highly efficient for detecting and monitoring populations of rare and threatened saproxylic insect species that are difficult to observe with traditional survey methods (Larsson and Svensson 2009; Kadej et al. 2015; Burman et al. 2016; Harvey et al. 2017). In addition to mapping and monitoring populations, data collected from pheromone-based trapping can be used to study more complex questions associated with the 
optimal management of habitats, and the resource requirements of threatened insect species at landscape or local scales (Musa et al. 2013). To date, most research employing pheromone-based sampling methods has focused on saproxylic beetles dependent on hollow tree cavities (Larsson and Svensson 2009; Andersson et al. 2014), in large part because pheromones or related attractants have not been identified for other possible species of interest. However, the studies cited above have clearly demonstrated the value of pheromone-based methods as sensitive and highly efficient tools for sampling rare and cryptic species, providing substantial incentive to identify the pheromones of other rare or threatened species with different ecological demands (Larsson 2016; Larsson and Molander 2016). Pheromone-based monitoring could aid significantly in overcoming several key impediments to insect conservation, particularly in addressing the urgent need for more accurate information on the distribution and population changes of threatened species (Cardoso et al. 2011).

Longhorn beetles (Cerambycidae) are a useful group of model species for ecological and conservation research in forest ecosystems. In particular, the large numbers of species that have adapted to a variety of ecological niches provide a multitude of interesting model species that indirectly deliver information on the availability and status of specific habitats and wood substrates within an area. Owing to the group's popularity with natural historians and collectors, the habitat and substrate requirements (in a broad sense) are relatively well-known for many species (Linsley 1959; Ehnström and Holmer 2007; Klausnitzer et al. 2016), and historic population trends are comparatively well documented in certain regions for at least some species. These data show that many species have declined as a consequence of rapid, widespread environmental changes (McCorquodale et al. 2007; Jeppsson et al. 2010; Cálix et al. 2018).

Rapidly accumulating data have shown that longhorn beetles make extensive use of long-range attractant pheromones (Millar et al. 2009; Hanks and Millar 2016). The compounds are often shared by multiple species, and are usually fairly simple structures (Millar and Hanks 2017). Traps baited with cerambycid pheromones have proven to be efficient for sampling, and can easily be designed for catch and release purposes, depending on the status of the species being studied. Thus, longhorn beetles constitute excellent candidates for pheromone-based field studies of threatened forest insects. However, to date, although pheromones or likely pheromones have been identified from several hundred cerambycid species (Hanks and Millar 2016), pheromones have only been reported for a small number of rare or threatened species, such as a few species of the Prionus genus (Barbour et al. 2011), Desmocerus californicus ssp. dimorphus (Ray et al. 2014), Dryobius sexnotatus (Diesel et al. 2017), Rosalia alpina (Žunič Kosi et al. 2017), Phymatodes pusillus ssp. pusillus
(Molander and Larsson 2018), and Plagionotus detritus ssp. detritus (Molander et al. 2019).

Anaglyptus mysticus (Linnaeus, 1758) and Xylotrechus antilope ssp. antilope (Schönherr, 1817) (henceforth, this subspecies will be referred to as $X$. antilope) are two cerambycid species (Cerambycinae; Clytini) of interest to conservation biology, especially in Northern Europe where the species are considered rare and occur in local populations (Ehnström and Axelsson 2002; Ehnström and Holmer 2007). Anaglyptus mysticus is present in southern Sweden, Denmark, the Baltic states, and in a small area of southern Norway (Laugsand et al. 2008; Danilevsky 2018). Xylotrechus antilope is only present in two small, isolated, and disjoint areas, one in southeastern Sweden, and one in southern Norway (Ehnström and Holmer 2007). Both species have been assessed as near threatened (NT) on the Swedish national Red List (ArtDatabanken 2015), and A. mysticus as critically endangered (CR) in Norway (Odegaard et al. 2015). Habitat fragmentation and loss of suitable substrates are the main (known) threats to their continued survival in these areas (ArtDatabanken 2015; Odegaard et al. 2015). The two species mainly inhabit deciduous forests and woodlands, but have different substrate preferences, with A. mysticus mainly developing in dead branches of hazel (Corylus avellana), in addition to a number of other deciduous trees, whereas $X$. antilope is dependent on fresh, recently dead oak branches (mainly Quercus robur) (Ehnström and Axelsson 2002). Both species are difficult to observe unless substantial amounts of fresh wood are present, that can be inspected visually on days with favorable weather. Thus, identification of the pheromones of these species could greatly facilitate detection and population monitoring, as well as a variety of ecological field studies on these species. The pheromone chemistry of A. mysticus has not been studied previously, but Schröder (1996) identified a number of compounds from extracts of volatiles from male $X$. antilope (ssp. antilope), some of which may function as pheromone components. However, to our knowledge, behavioral assays to confirm the identity and composition of a pheromone for the latter species have not been reported.

In this study, we demonstrate that males of A. mysticus produce a two-component blend of $(R)$-3-hydroxy-2-hexanone and 2-nonanone as an aggregation-sex pheromone that attracts conspecific females and males. Further, we confirm that males of $X$. antilope produce (S)-2-hydroxy-3-octanone, and show that this single component is an aggregation-sex pheromone which attracted both female and male beetles in field trials. 


\section{Methods and materials}

\section{Study sites}

For field work (collection of substrates with larvae and bioassays), two different study areas were used, one for each species (for details on the individual sites, see Online Resource 1, Tables S1 and S2). Anaglyptus mysticus was studied on the Swedish island of Öland in the Baltic Sea, Kalmar County. Several sites were used for collection of infested wood and insect trapping in the southern part of the Mittland forest (approximate center coordinates: DD $56.6800 \mathrm{~N}, 16.6027 \mathrm{E}$ ). The area consists of a diverse mixture of dense forest stands managed for production of timber and forest biofuel, interspersed with grazed woodlands, semi-natural grasslands, and agricultural fields. Hazel (C. avellana), pedunculate oak ( $Q$. robur), European ash (Fraxinus excelsior), and elm (Ulmus spp.) dominate the tree cover. Anaglyptus mysticus occurs throughout the Mittland forest and is fairly abundant; no other area in Sweden has a higher number of recent observations of this species (see Lindhe et al. 2010; Swedish Species Observation System 2018a). The species' comparatively high abundance in the Mittland forest may be explained by the large quantities of old hazel bushes present, because decaying hazel wood appears to be the preferred substrate of the larvae in Sweden (Ehnström and Holmer 2007). Therefore, we also focused on this tree species for collecting wood to rear out $A$. mysticus (see below).

Xylotrechus antilope was studied at Ecopark Hornsö (approx. center coordinates: DD 57.0120N, 16.0897E) on the Swedish mainland, Kalmar County. The Ecopark comprises a mixed coniferous-deciduous forest of $\sim 9200$ hectares that is one of the most important areas for rare and red-listed saproxylic insects in Northern Europe (Nilsson 2001; Anonymous 2008). The forest is predominantly managed for timber production, but several nature reserves have been established and management practices are tailored to support biodiversity throughout the area (Anonymous 2008). Small, open grasslands, rocky areas, and lakes and streams of different sizes increase the landscape's heterogeneity. Young and middle-aged pedunculate oak trees are abundant and $X$. antilope is a common and widespread species within the Ecopark (Nilsson and Huggert 2001; MAM, pers. obs.), which may harbor the largest population of this species in Northern Europe (Nilsson and Huggert 2001).

\section{Collection of beetles}

Hazel wood with larvae of Anaglyptus mysticus was collected from three different locations in the Mittland forest in early December 2015. At each location, we sought to collect different types of dead hazel wood because we did not know which logs might contain developing larvae, or the preferred stage of decay. Thus, substrates in different decay stages were collected, from relatively fresh, hard wood to decaying wood that could easily be broken up with a knife. Diameters varied from $\sim 3$ to $12 \mathrm{~cm}$. We collected standing and fallen hazel wood stems, from both sun-exposed and shady positions. In all, $\sim 1$ cubic meter of hazel wood was gathered. The collected wood samples represented only a small proportion of the entire amount of dead hazel wood present at each of the three surveyed sites.

The collected wood was cut into $\sim 0.5-\mathrm{m}$ sections and placed in transparent plastic containers $(\mathrm{L} \times \mathrm{W} \times \mathrm{H}$ : $56 \times 39 \times 42 \mathrm{~cm}$ ). From late December, the containers were kept in a greenhouse with an average daily temperature of about $15^{\circ} \mathrm{C}$ and examined twice daily for emerging beetles. Occasionally, a spray bottle was used to dampen the wood with water to reduce desiccation. The first individuals of A. mysticus emerged from the wood after about 4 weeks (in early February). Adults continued to emerge for about a week until a total of 29 individuals had emerged. The beetles were continuously removed from the boxes, separated by sex, and stored in two plastic containers with fresh pieces of hazel branches (C. avellana), in an effort to stimulate pheromone release. For nourishment, we added pieces of paper saturated with honey water, and exchanged them for new ones every second day. The beetles were sexed by comparing the length of the antennae to the length of the body (from the mouthparts to the tip of the abdomen); males of A. mysticus have antennae of a greater relative length than females (Hansen 1966). The containers were stored in a refrigerator $\left(8^{\circ} \mathrm{C}\right)$ before (and sometimes in between) collections of headspace odors.

Xylotrechus antilope was reared from wood substrates collected on two occasions in Ecopark Hornsö. In the early spring of 2011, freshly cut branches of pedunculate oak $(Q$. robur) collected from various sources in the southern Swedish counties of Skåne, Blekinge, and Kalmar were transported to Lindsudd near Barnebo Lake (Barnebo N, Online Resource 1, Table S2), held outdoors through the summer, and collected again in the autumn, after natural colonization by the insects. The wood was stored outdoors and brought into a greenhouse in early 2012. In 2015, substrates were collected from a large heap of dead twigs and branches (up to $\sim 20 \mathrm{~cm}$ diameter) of pedunculate oak at Ecopark Hornsö (Barnebo NE, Online Resource 1, Table S2). The substrates were left-over wood residues from logging activities in an adjacent mature oak forest in the winter of 2013-2014. A large number of saproxylic insects had colonized the wood in the summer of 2014, when it had been left to dry along a sunny south-facing forest edge. Once dry, the material 
would eventually be shredded as biofuel, which occurred in late winter 2015. Thus, the heap of substrates formed a socalled ecological trap, as described by Hedin et al. (2008). In February 2015, before several species with short larval developmental times were about to emerge from the wood in the following summer season, we collected $\sim 1.5$ cubic meters of wood substrates of mixed dimensions from the top and sides of the heap, which were brought back to the SLU campus and held in a greenhouse. In both 2011 and 2015, the wood material was processed as described for $A$. mysticus (see above).

In both 2012 and 2015, the first individuals of $X$. antilope emerged after about 3 weeks in the greenhouse, and large numbers of adults continued to emerge over about 1 week. The numbers of emerging beetles were quantified only in 2015 , when a total of $527 X$. antilope emerged, of which a subset of about 25 individuals (selected at random from multiple containers with wood, and initially stored singly in tubes) was used for headspace sampling (see below). The roughly 25 individuals that were selected to be used for aerations (the technique used for collecting volatile compounds emitted by the insects, see below) were separated by sex and stored in two plastic containers with pieces of fresh oak branches and slips of paper soaked in honey water. Since females and males of $X$. antilope have nearly identical external morphology, to sex the beetles, we put two individuals (from the group of $\sim 25$ individuals) together in a small container and observed if the animals attempted to copulate. In most cases, when a male and female were put together, copulation was initiated immediately after the male first touched the female with his antennae. If the beetles did not make physical contact after $\sim 0.5 \mathrm{~min}$, or if they made physical contact but did not start to copulate, we excluded the animals and continued with a new pair of individuals. The containers with males and females (about ten individuals of each sex) were stored in a refrigerator before headspace collections (see below).

\section{Collection of volatiles}

We performed headspace sampling using the same approach and equipment for both study species. The beetles, in their containers with males and females separated, were transferred from the refrigerator to a climate-controlled chamber $\left(25{ }^{\circ} \mathrm{C}\right.$ constant temperature, light 8:30 AM-9 PM, 65\% relative humidity) in the afternoon of the day before aerations were to commence. The next morning, 5-8 individuals of each sex were picked randomly and placed in two $1 \mathrm{~L}$ gas washing bottles (males and females in separate bottles) (Lenz Laborglas Gmbh, Wertheim, Germany). An identical, but empty bottle was used as a blank control. Strips of a fine metal mesh (previously rinsed with ethanol and acetone) were inserted into the bottles to increase the surface area over which the beetles were distributed to reduce the risk of aggression. The bottles were then transferred to a second climate chamber (but with the same settings), and headspace sampling was initiated.

Detailed specifications of the materials and techniques used for the headspace sampling can be found in Molander and Larsson (2018). Briefly, collectors consisted of Porapak $^{\mathrm{TM}} \mathrm{Q}$ adsorbent, enclosed in Teflon ${ }^{\circledR}$ tubing, and attached with Teflon ${ }^{\circledR}$ thread-sealing tape to one of the two top openings of each glass bottle. An identical collector was attached to the second opening of each bottle to remove volatiles from the incoming air. Polyvinyl chloride (PVC) tubing, plastic connectors, and Teflon ${ }^{\circledR}$ tape were used to connect the three collectors to a single air pump. A constant flow rate of 0.25 $\mathrm{L} \mathrm{min}^{-1}$ through each collector was established using a triple air flow meter and plastic valves on the PVC tubing. Two sets of glass bottles and several sets of collectors were alternated between different aerations, to avoid systematic errors. In between aerations, the bottles were rinsed with ethanol followed by acetone, and occasionally placed in an oven $\left(400^{\circ} \mathrm{C}\right)$ overnight.

Aerations lasted for about 5-6 h ( 10 AM to 4 PM) because both species are diurnal with maximal activity in the late morning to early afternoon under field conditions (MAM, pers. obs.). In between aerations, the beetles were released back into the containers with fresh wood where they mixed with other same-sex individuals. Thus, most collections were carried out with mixtures of new and previously aerated individuals. After headspace collections had been initiated, the beetles were stored in the original climate chamber in between aerations (or in the refrigerator if aerations were not performed on consecutive days). A total of 4 headspace collection sessions were conducted with A. mysticus and 7 with $X$. antilope, with each session consisting of a collection from males, females, and a blank control sample.

Immediately after aeration, collectors were extracted with $300 \mu \mathrm{l}$ of hexane, then washed with an additional $3 \times 300 \mu \mathrm{l}$ of hexane followed by $3 \times 300 \mu \mathrm{l}$ of acetone, before reuse. The extracts, in vials with closed butyl/PTFE seal screw caps (articles 11,090,210 and 08,151,653, Skandinaviska Genetec $\mathrm{AB}$, Stockholm, Sweden), were kept in a freezer $\left(-18{ }^{\circ} \mathrm{C}\right)$ until analysis by gas chromatography-mass spectrometry (GC-MS; see below).

\section{Identification of compounds}

Extracts of volatiles from both species were analyzed with the same methods and GC-MS instruments. At the Alnarp campus, a $6890 \mathrm{~N}$ model GC interfaced to a 5975 mass selective detector (Agilent Technologies, Palo Alto, CA, USA) was used, with the transfer line temperature set at $150{ }^{\circ} \mathrm{C}$. The GC was fitted with an HP-5ms capillary column (95\% polydimethylsiloxane/5\% phenylmethylsiloxane, 
$60 \mathrm{~m} \times 0.25 \mathrm{~mm}$ inner diam., $0.25 \mu \mathrm{m}$ film thickness, Agilent Technologies). Injections of $2 \mu \mathrm{l}$ of each aeration sample were made manually in splitless mode (split vent opened after $0.5 \mathrm{~min}$, injector temperature $225^{\circ} \mathrm{C}$ ). Control injections of $2 \mu \mathrm{l}$ of hexane were performed before and in between analyses of headspace samples. The carrier gas was helium with a constant flow rate of $1.8 \mathrm{ml} \mathrm{min}^{-1}$ (inlet pressure $172 \mathrm{kPa}$ ). The oven program started at $30^{\circ} \mathrm{C}$, with a $3 \mathrm{~min}$ hold, thereafter rising by $8{ }^{\circ} \mathrm{C} \mathrm{min}^{-1}$ to $260{ }^{\circ} \mathrm{C}$, with a $10 \mathrm{~min}$ hold. We also analyzed the extracts on a second GC-MS (GC model 7890B and MS model 5977Agilent Technologies) equipped with a DB-WAX capillary column (polyethylene glycol, $60 \mathrm{~m} \times 0.25 \mathrm{~mm}$ inner diam., $0.25 \mu \mathrm{m}$ film thickness; J\&W Scientific, Folsom, CA, USA). Injections, carrier gas, and settings were identical to those used with the HP-5ms column, except that the flow rate was $1.9 \mathrm{ml} \mathrm{min}{ }^{-1}$, and the final temperature was $230^{\circ} \mathrm{C}$. The mass spectrometers were set with a solvent delay of $7 \mathrm{~min}$. Spectra were taken in electron impact ionization (EI) mode at $70 \mathrm{eV}$, with a scanning range of $29-400 \mathrm{~m} / \mathrm{z}$.

Calculations of the relative proportions of potential pheromone compounds (see "Results") were based on the results from the DB-WAX column for A. mysticus because the trace components separated better on this column, and the HP-5ms column for X. antilope. Due to the temperatures used during analyses, we observed that one of the main pheromone components, 3-hydroxy-2-hexanone, was partially rearranged into 2-hydroxy-3-hexanone on both columns, with peaks partially separated on the DB-WAX column. We therefore pooled the peak areas of the two isomers from the DB-WAX chromatogram to achieve a combined estimate of the relative quantities of pheromone compounds produced by A. mysticus. When extracts were analyzed at lower temperatures on a chiral stationary phase GC column (see below), essentially a single peak corresponding to 3-hydroxy-2-hexanone was observed.

Extracts of volatiles were also analyzed at UC Riverside by GC-MS using an Agilent 7820A GC interfaced to a 5977E mass selective detector, and an autosampler. The GC was equipped with a DB-5 column (95\% polydimethylsiloxane $/ 5 \%$ phenylmethylsiloxane, $30 \mathrm{~m} \times 0.25 \mathrm{~mm}$ inner diam., $0.25 \mu \mathrm{m}$ film thickness; J\&W Scientific). One $\mu$ linjections were made in splitless mode (injector $250{ }^{\circ} \mathrm{C}$, transfer line $280^{\circ} \mathrm{C}$, split vent opened after $0.5 \mathrm{~min}$ ), with helium carrier gas (inlet pressure $89.6 \mathrm{kPa}$, linear velocity $34 \mathrm{~cm} / \mathrm{sec}$ ). The oven was programmed from $40{ }^{\circ} \mathrm{C}$ for $1 \mathrm{~min}, 10{ }^{\circ} \mathrm{C} \mathrm{min}-1$ to $280^{\circ} \mathrm{C}$, hold $20 \mathrm{~min}$. Mass spectra were taken in EI mode at $70 \mathrm{eV}$, scanning a mass range from $40-450 \mathrm{~m} / \mathrm{z}$, with a 3 min solvent delay.

The chromatograms from extracts of males, females, and controls were compared visually with Agilent ChemStation software (version E.02.02.1431) using the overlay function. The observed sex-specific peaks were first tentatively identified by matching their mass spectra to reference spectra in the Wiley (10th edition) and NIST (NIST 14) commercial mass spectral databases where possible, and/or to reference spectra from previous work with cerambycid semiochemicals. The identities were then confirmed by comparing mass spectra and retention times to those of authentic standards.

The absolute configurations of the insect-produced compounds were determined by analyses of aliquots of the extracts at UC Riverside using a GC equipped with a chiral stationary phase Cyclodex B GC column $(10.5 \%$ $\beta$-cyclodextrin in DB-1701, $30 \mathrm{~m} \times 0.25 \mathrm{~mm}$ inner diam., $0.25 \mu \mathrm{m}$ film thickness, J\&W Scientific), with an injector temperature of $150{ }^{\circ} \mathrm{C}$ to minimize isomerization of the thermally labile hydroxyketones. Injections were made in split mode (split ratio 20:1) at $172 \mathrm{kPa}$ inlet pressure, with a temperature program of $50{ }^{\circ} \mathrm{C} / 1 \mathrm{~min}, 3^{\circ} \mathrm{C} / \mathrm{min}$ to $220^{\circ} \mathrm{C}$, hold $20 \mathrm{~min}$. The GC was equipped with a flame ionization detector (detector temperature $250{ }^{\circ} \mathrm{C}$ ), and chromatograms were processed with Peak Simple software (SRI Instruments, Torrance, CA, USA). Authentic standards were analyzed using identical parameters, and the identification of the insect-produced enantiomer of each hydroxyketone was verified by coinjection of a blend of the insect extracts with the racemic standards, determining which of the two peaks in each racemate was enhanced.

\section{Sources of chemicals}

Racemic 3-hydroxy-2-hexanone (CAS number: 54123-750 ) was purchased from Bedoukian Research (Danbury, CT, USA). Standards of 2-nonanone (99\% purity, CAS: 82155-6), 2-heptanone (99\%, CAS: 110-43-0), 2-undecanone (99\%, CAS: 112-12-9) and 2-nonanol (99\%, CAS: 62899-9) were obtained from Sigma-Aldrich (Hamburg, Germany), and 2,3-hexanedione (90\%, CAS: 3848-24-6) from Aldrich Chemical Co. (Milwaukee, WI, USA). Racemic 2-hydroxy-3-octanone was synthesized from racemic lactic acid methyl ester (TCI America, Portland, OR, USA), and (S)-2-hydroxy-3-octanone was synthesized from $(S)$-lactic acid methyl ester, using methods previously described by Hall et al. (2006). An authentic standard of 2,3-octanedione was produced by oxidation of a few $\mathrm{mg}$ of $(S)$-2-hydroxy3-octanone with pyridinium dichromate in dichloromethane.

\section{Field bioassays}

The biological activity of the identified compounds was examined in three separate field bioassays. For A. mysticus, we used racemic 3-hydroxy-2-hexanone and 2-nonanone because pure $(R)$-3-hydroxy-2-hexanone was not available when the bioassays were conducted. For $X$. antilope, racemic 2-hydroxy-3-octanone was used in 2015, whereas (S)-2-hydroxy-3-octanone was used in 2016. We choose to exclude 
2,3-hexanedione and 2,3-octanedione from our bioassays because these compounds are likely to be artefacts from degradation of the corresponding ketols (Millar and Hanks 2017). In addition, we did not test a number of trace components (see "Results") in the extracts of male A. mysticus.

Five treatments were used in the bioassay with A. mysticus in 2017, including racemic 3-hydroxy-2-hexanone and 2-nonanone as single components at $100 \mathrm{mg}$ and $100 \mathrm{mg}$ per $\mathrm{ml}$ in isopropanol, respectively, and three blends with variable quantities of 2-nonanone to that of the racemic hydroxyketone $(20: 100,50: 100$, and 80:100 $\mathrm{mg} / \mathrm{ml}$ respectively, in isopropanol). Thus, the resulting proportions of 2-nonanone to the insect-produced $(R)$-enantiomer of 3-hydroxy-2-hexanone were 40:100, 100:100, and 160:100. Polyethylene Grippie $^{\circledR}$ zip-lock bags $(6.5 \mathrm{~cm} \times 5.5 \times 40 \mu \mathrm{m}$, Grippie Light $\mathrm{Nr}-02$, b.n.t. Scandinavia AB, Arlöv, Sweden) were used as dispensers. At the field sites, $0.5 \mathrm{ml}$ of each treatment was loaded into each bag, and the bag was attached with wire to the south-facing side of the trap without puncturing the bag. A detailed description of the custom-built flightintercept traps that were used in all bioassays can be found in Molander et al. (2019). The traps had two cross-vane panels mounted atop a funnel that emptied into a collecting jar, and a top cover for rainwater protection. The panels and the inside of the funnel were coated with Fluon ${ }^{\circledR}$ (polytetrafluoroethylene dispersion, $60 \mathrm{wt} \%$ in $\mathrm{H}_{2} \mathrm{O}$, Sigma-Aldrich, St. Louis, Missouri, USA, further diluted 1:1 with water) to increase trap efficiency (see, e.g., Graham and Poland 2012). Each trap contained $\sim 0.25 \mathrm{~L}$ propylene glycol as a preservative and killing agent.

Six replicates (sites) were used in the bioassay with $A$. mysticus, each consisting of one trap with each of the five treatments and a control trap (with a lure of $0.5 \mathrm{ml}$ of isopropanol alone). The traps were deployed in linear transects at six sites in the Mittland forest on April 29 and positioned in glades or along sunny forest edges with large amounts of hazel in the immediate vicinity. Replicates were separated by a minimum of $300 \mathrm{~m}$ and posts of reinforcement steel were used to hang the traps in a row with $10 \mathrm{~m}$ between traps. The center of each trap, and the location of the pheromone lure, was $\sim 1.5 \mathrm{~m}$ above ground. All replicates were checked three times (May 21, June 10, and July 2) resulting in three sampling periods which covered the main activity period of the species in southeastern Sweden (Lindhe et al. 2010).

For $X$. antilope, racemic 2-hydroxy-3-octanone was tested at $100 \mathrm{mg} / \mathrm{ml}$ of isopropanol (2015), whereas $(S)$-2-hydroxy3-octanone was tested at $50 \mathrm{mg} / \mathrm{ml}$ (2016). Consistent with A. mysticus, Grippie ${ }^{\circledR}$ zip-lock bags were loaded with $0.5 \mathrm{ml}$ of test solutions and control lures were loaded with $0.5 \mathrm{ml}$ of isopropanol alone. In 2015, four replicates (sites) were deployed in Ecopark Hornsö, separated by $600 \mathrm{~m}$ or more. The traps were suspended from protruding oak branches at a height of $\sim 1.5-2 \mathrm{~m}$ and the traps within each replicate were separated by $\sim 10$ to $20 \mathrm{~m}$. Two sampling periods were used. For the first sampling period, three replicates were deployed on May 29 and the fourth replicate on May 30. Three replicates were checked on June 24 and the fourth replicate on June 25 . The second sampling period ended on July 26 when the traps were emptied a second time and taken down. Late July marks the end of the species' main activity period in Sweden (Lindhe et al. 2010). In 2016, when pure (S)-2-hydroxy-3-octanone was tested, five replicates were deployed in the Ecopark. Most sites were not the same as in 2015 and sites were separated by at least $1.1 \mathrm{~km}$. In 2016, traps were hung from steel posts (see above) and spaced $10 \mathrm{~m}$ apart within each replicate. Only a single sampling period was used with all replicates deployed on June 5. Two replicates were checked on June 28 and three replicates on June 30.

In all three bioassays, the positions of the lures were randomized within the replicates at deployment, and each replicate for A. mysticus was re-randomized after the first and second sampling periods. For $X$. antilope, we switched the position of the treatment and the control after the first sampling period in 2015. Tea filters were used to separate the insects from the propylene glycol. The glycol was reused, while the filters with the insects were saved in plastic bags with details on site, date, lure, etc. recorded on each bag. After each sampling period, new pheromone lures were added to all traps by attaching a new Grippie ${ }^{\circledR}$ zip-lock bag.

Furthermore, in 2017 we undertook a large-scale landscape study (unpublished) of $X$. antilope and other longhorn beetles at 68 sites in southern Sweden that consisted of forests and woodlands dominated by mature oak trees (mainly Q. robur) (for locations see Fig. 5 and Online Resource 1, Table S3). At each site, we used three traps with (S)-2-hydroxy-3-octanone (50 $\mathrm{mg} / \mathrm{ml}$ isopropanol) and three traps with a blend of heterospecific cerambycid pheromone compounds consisting of racemates of 3-hydroxy-2-hexanone (100 mg/ml isopropanol; from Bedoukian Research, see above), 3-hydroxy-2-decanone [ $20 \mathrm{mg} / \mathrm{ml}$; synthesized as described in Allison et al. (2012)] and 3-hydroxy-2-octanone [10 mg/ml; made as described in Imrei et al. (2013)]. Traps (of the same type as used in the bioassays and hung from steel posts at all sites with polypropylene glycol as a preservative) were spaced $\sim 10 \mathrm{~m}$ apart and lure treatments were assigned randomly. Lure solutions $(0.5 \mathrm{ml} / \mathrm{lure})$ were loaded into Grippie ${ }^{\circledR}$ zip-lock bags as above. All traps were deployed during the peak of the activity period of $X$. antilope (7-12 June), and emptied once (28 June-3 July) when trapping was terminated. The specimens of $X$. antilope that were captured in this study were used to compare the trapping efficiency of the species' own pheromone to that of the blend of heterospecific pheromone compounds.

The numbers of A. mysticus and X. antilope per sample were counted and the sex ratio determined in a subset of samples (see "Results") from the bioassays. The key by 
Ehnström and Holmer (2007) was used to identify specimens. For A. mysticus, the sex was mainly determined by the relative length of the antennae (see above), but $\sim 15$ specimens were also dissected to confirm that the character was reliable. For $X$. antilope, every beetle in the subset was dissected and the genitalia were studied to confirm the sex. The trapped beetles are preserved in $70 \%$ ethanol and voucher specimens will be deposited in the public Lund entomological collections (Biological Museum, Lund University, Sweden).

\section{Statistical analysis}

To analyze trap catches of $A$. mysticus, the effects of the five different lure treatments were compared to the control in a Generalized Linear Mixed Model (GLMM) using a Poisson distribution and a $\log _{e}$ link function. The model compared how the number of captured A. mysticus (response variable) depended on lure treatment (fixed factor) and was set up with replicate (six sites) and sampling period (three trap counts) as random effects to control for dependencies. The model was checked for over- and underdispersion using Pearson residuals. The resulting dispersion statistic $(\varphi=1.24)$ was deemed acceptable (cf. Hilbe 2011), with no need for model corrections. The different treatments and the control were then compared by multiple pairwise post hoc tests (Tukey's $H S D$ test), using least squares means with the package emmeans (Lenth 2018). Flight activity of A. mysticus was low during the first sampling period (early May) and four replicates where no beetles were captured during this sampling period were omitted from the analyses (and Fig. 3).

GLMMs with Poisson distributions were also used to compare the treatment with the control for each of the two bioassays with $X$. antilope. A $\log _{e}$ link function was used for the 2015 dataset, but exchanged for a square root link function in the 2016 dataset, because no beetles were caught in any control traps. For the 2015 dataset, replicate (four sites) and sampling period (two trap counts) were used as random effects, while only replicate (five sites) was used for the 2016 dataset. Dispersion statistics were calculated for both models using Pearson residuals and deemed negligible ( $\varphi=1.05$ for $2015, \varphi=1.17$ for 2016). Finally, a GLMM with Poisson distribution and $\log _{e}$ link function was used to compare captures of $X$. antilope baited with the species' own pheromone versus traps baited with the blend of heterospecific cerambycid compounds in the 2017 landscape study, with site as a random effect. Pearson residuals were used to calculate the models' dispersion statistic, which was satisfactory $(\varphi=1.23)$.

Statistical significance was defined as probability values $(P)$, or adjusted probability values $\left(P_{\mathrm{a}}\right)$ for post hoc tests, of less than 0.05 . All statistical analyses were performed in
$\mathrm{R}$ version 3.5.1 for Windows (R Core Team 2018) with the lme4 package for GLMMs (Bates et al. 2015).

\section{Results}

\section{Identification of insect-produced compounds}

Analysis by gas chromatography-mass spectrometry showed that a total of nine insect-produced compounds were consistently present in, and specific to, all four extracts from male beetles of A. mysticus (Fig. 1). The two compounds that were present in the highest mean proportions were identified as 3-hydroxy-2-hexanone and 2-nonanone (Table 1), and the absolute configuration of the 3-hydroxy-2-hexanone was determined to be $(R)$. In three extracts, 2-nonanone was present in lower quantities than $(R)$-3-hydroxy-2-hexanone, while one sample contained essentially equal quantities, indicating that $(R)$-3-hydroxy-2-hexanone was the major component. Further, 2,3-hexanedione was present in low amounts in all extracts from males. Only trace quantities of the remaining 5-6 male-specific compounds were observed (depending on which GC column was used). The three trace compounds with the highest mean proportions relative to the major component were identified as 2-heptanone, 2-undecanone, and 2-nonanol (Table 1). The remaining three trace compounds occurred in even lower amounts, and were not identified.

For $X$. antilope, two compounds were present in all seven extracts from male beetles, but missing in all corresponding extracts from females and blank controls (Fig. 2). The two compounds were identified as $(S)$-2-hydroxy-3-octanone and 2,3-octanedione, with $(S)$-2-hydroxy-3-octanone being the major component (Table 1). No other male-specific compounds were detected in extracts from either of the two species, no female-specific compounds were detected, and no compounds were consistently detected in extracts from both males and females of either species, but missing in the blank controls.

\section{Field bioassays}

A total of 121 individuals of A. mysticus were captured in the field bioassay. From the GLMM analysis, all three blends of racemic 3-hydroxy-2-hexanone and 2-nonanone attracted significantly more $A$. mysticus than the control, whereas the numbers of beetles attracted to the individual compounds were not significantly different from the control (Online Resource 1, Table S4). In the pairwise post hoc comparisons, the two blends with higher proportions of 2-nonanone to the $(R)$-enantiomer of the hydroxyketone (100:100 and 160:100, respectively), attracted significantly more $A$. mysticus than the control and the individual compounds (Fig. 3, 


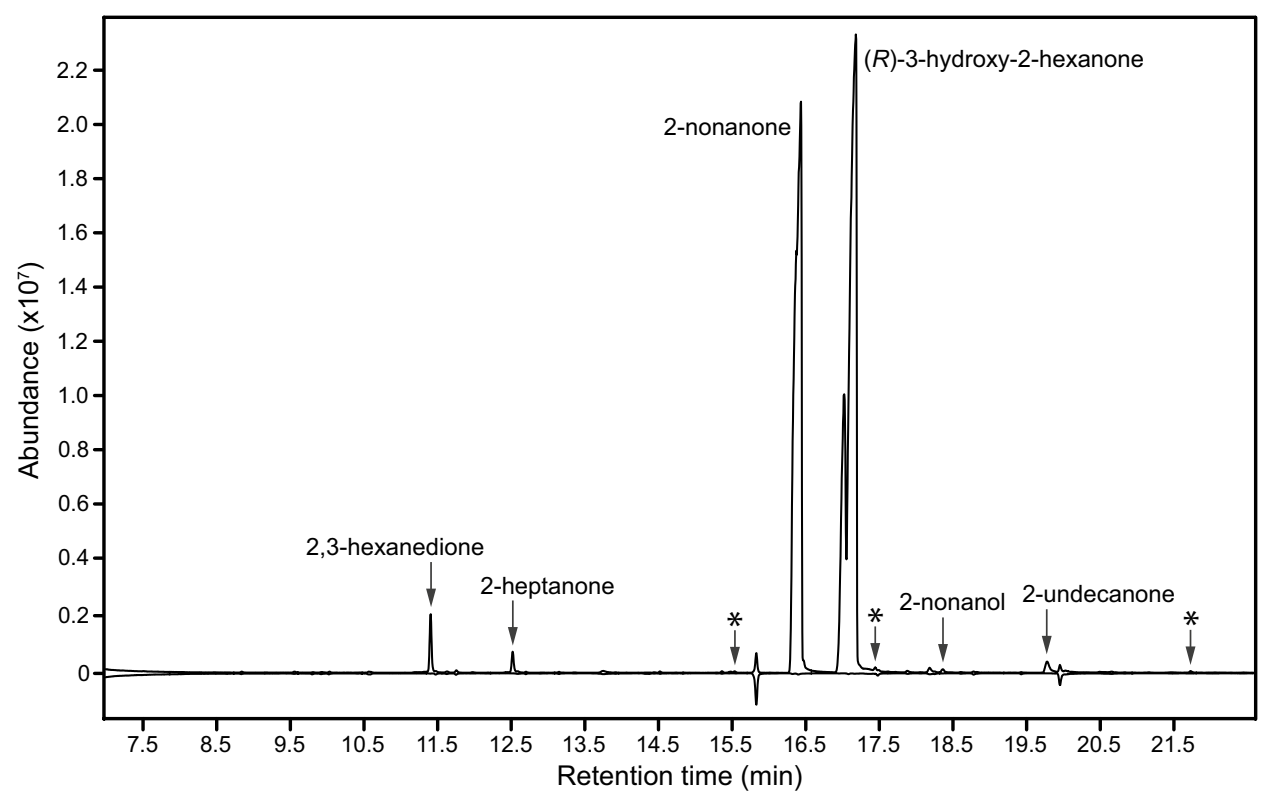

Fig. 1 Representative total ion chromatograms (DB-WAX column) of headspace volatiles collected from adult male (top trace) and female A. mysticus (bottom, inverted trace). Two compounds ( $R$ )-3-hydroxy2-hexanone and 2-nonanone, were consistently present in large quantities in samples from males. In addition, minor quantities of 2,3-hexanedione and six trace compounds were also repeatedly found in samples from males. The three most abundant trace compounds were

Table 1 Overview of compounds consistently present and specific to the extracts of volatiles from male beetles of A. mysticus and X. antilope

\begin{tabular}{lll}
\hline Species & Compound & Mean proportion $( \pm \mathrm{SE})$ \\
\hline A. mysticus & $($ R)-3-hydroxy-2-hexanone & 100 \\
& 2-nonanone & $70.0( \pm 11.0)$ \\
& 2,3-hexanedione & $4.0( \pm 1.0)$ \\
& 2-heptanone & $1.2( \pm 0.5)$ \\
& 2-undecanone & $0.7( \pm 0.1)$ \\
& 2-nonanol & $0.3( \pm 0.2)$ \\
X. antilope & $(S)$-2-hydroxy-3-octanone & 100 \\
& 2,3-octanedione & $4.0( \pm 1.1)$ \\
\hline
\end{tabular}

The mean proportion of the less-abundant compounds is expressed relative to the main pheromone component of each species $(100) ;(R)-$ 3-hydroxy-2-hexanone and (S)-2-hydroxy-2-octanone, respectively. There were four extracts from A. mysticus males and seven from $X$. antilope males

Online Resource 1, Table S5). The sex ratio among individuals captured with the 160:100 blend was $40 \%$ males and 60\% females (total of 45 individuals).

In 2015, racemic 2-hydroxy-3-octanone attracted significantly more $X$. antilope (total 43 individuals) than the control (total of 2 individuals) (Fig. 4a, Online Resource 1, Table S6), and pure (S)-2-hydroxy-3-octanone was 2-heptanone, 2-nonanol, and 2-undecanone, whereas those present in even lower quantities were not identified (asterisks). Due to thermal rearrangement, the insect-produced $(R)$-3-hydroxy-2-hexanone was in part rearranged into 2-hydroxy-3-hexanone, with the latter compound forming a partially separate peak in front of $(R)$-3-hydroxy-2-hexanone

significantly more attractive (total of 44 individuals) than the control (no captured beetles) in 2016 (Fig. 4b, Online Resource 1, Table S6). The sex ratio in 2016 was 52\% males and $48 \%$ females.

Attraction of $X$. antilope also differed between the lures in the 2017 landscape study (Online Resource 1, Table S6). The traps with (S)-2-hydroxy-3-octanone captured a total of 1193 $X$. antilope $(5.85 \pm 0.44$ beetles/trap, mean $\pm \mathrm{SE})$, which was significantly more than the total 162 individuals $(0.79 \pm 0.10$ beetles/trap) in the traps with the blend of common heterospecific pheromone components. The traps with lures of the species' own pheromone detected $X$. antilope at 55 of the 68 surveyed sites, while traps with the blend of heterospecific compounds captured the species at 41 sites (Fig. 5).

\section{Discussion}

The consistent presence of high quantities of $(R)$-3-hydroxy2-hexanone and 2-nonanone in the headspace extracts from male A. mysticus, and high quantities of (S)-2-hydroxy3 -octanone in the extracts from male $X$. antilope, paired with the significant attraction of females and males of both species to the synthetic compounds tested in bioassays, demonstrate that these compounds function as male-produced aggregation-sex pheromones in these species. In A. mysticus, 
Fig. 2 Total ion chromatograms (HP-5ms column) of headspace volatiles collected from adult male (top trace) and female $X$. antilope (bottom inverted trace). Two sex-specific compounds (S)-2-hydroxy-3-octanone and 2,3-octanedione, were consistently present in extracts from male beetles

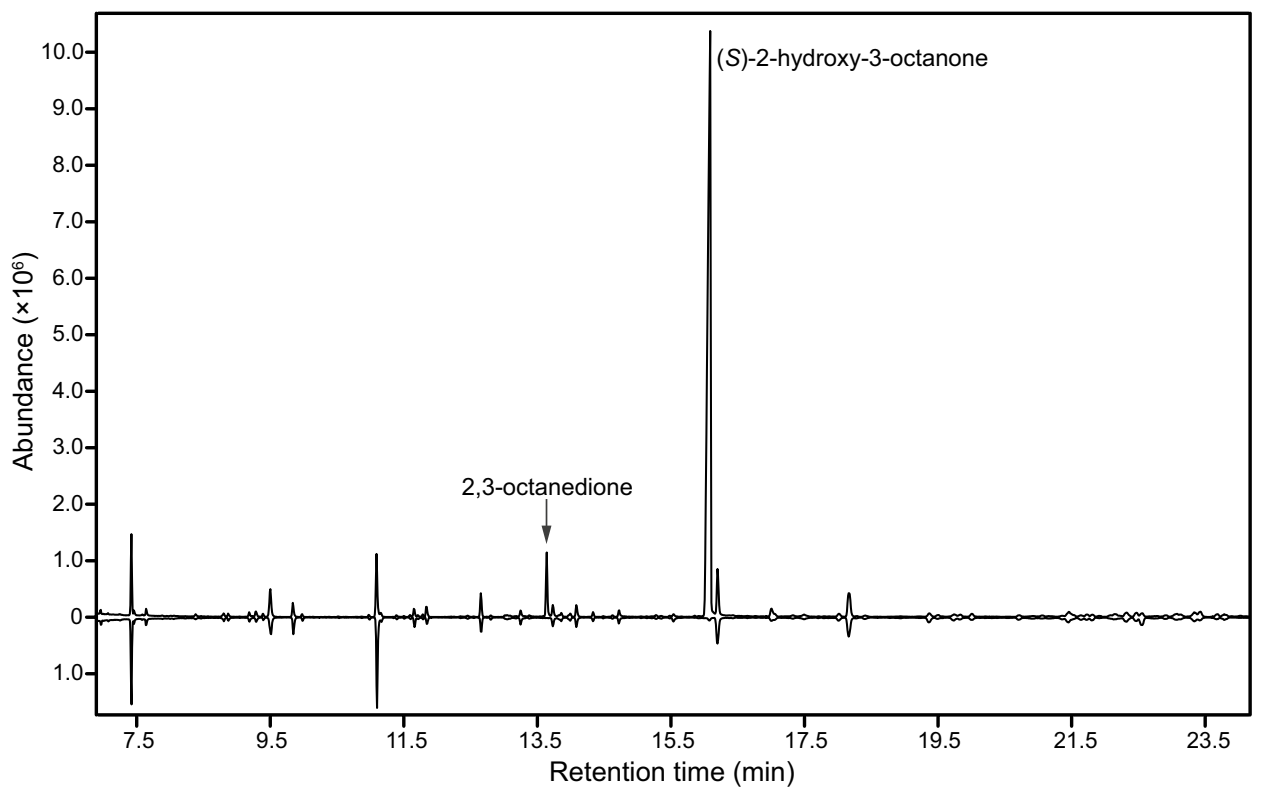

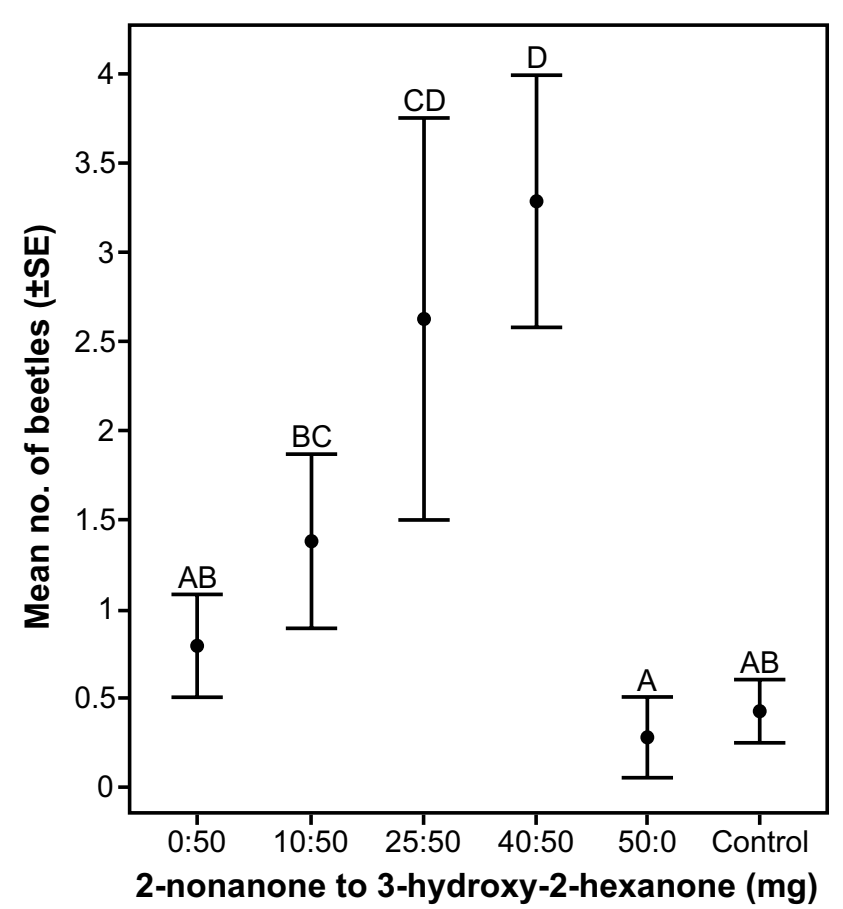

Fig. 3 Mean $( \pm \mathrm{SE})$ numbers of A. mysticus captured per trap and sampling period with different quantities of 2-nonanone and racemic 3-hydroxy-2-hexanone formulated in $0.5 \mathrm{ml}$ isopropanol $(n=14$ samples). Two treatments tested the compounds as single components (50 $\mathrm{mg}$ racemic 3-hydroxy-2-hexanone and $50 \mathrm{mg}$ 2-nonanone per lure, respectively), while three treatments consisted of blends with a variable quantity of 2-nonanone to the hydroxyketone's $(R)$-enantiomer (proportions 40:100, 100:100, and 160:100, respectively). The control was $0.5 \mathrm{ml}$ isopropanol alone. Mean values that do not share a common letter are significantly different $(P<0.05)$ the individual compounds were not attractive, but the two compounds acted synergistically when tested in blends with proportions of 100:100 or 160:100 of 2-nonanone to the naturally produced $(R)$-enantiomer of the hydroxyketone. In contrast, the blend with a lower proportion of 2-nonanone (40:100) appeared to be less attractive, indicating that both the presence of the two components and their relative proportions were important, analogous to what is seen in pheromone blends of other insects (e.g., moths; Löfstedt and Herrebout 1988).

Anaglyptus mysticus is the second cerambycid, and the first species of the Anaglyptus genus, reported to use 2-nonanone as a pheromone component, but the North American species Cyrtophorus verrucosus (Olivier, 1795) produces a blend of the same components as A. mysticus (Mitchell et al. 2013). Thus, these species represent another example of the general trend of pheromone compounds being conserved among related species of longhorn beetles, even when the species may have been spatially separated for millennia (Millar and Hanks 2017). The two genera belong to the same tribe (Anaglyptini), and the morphology of the two species is also similar; both species mimic the black and reddish brown coloration of several species of common wood ants (Formica spp. and Camponotus spp.).

Both racemic and pure $(S)$-2-hydroxy-3-octanone as a single compound proved attractive to $X$. antilope. However, the pheromone chemistry of $X$. antilope was first studied by Schröder (1996), who reported three male-specific compounds. As in our study $(S)$-2-hydroxy-3-octanone was the major component, but Schröder (1996) also reported lesser quantities of $(R)$ - and $(S)$-3-hydroxy-2-octanone, as well as trace quantities of the diastereomers of 2,3-octanediol (Schröder 1996). We did not observe these other compounds 


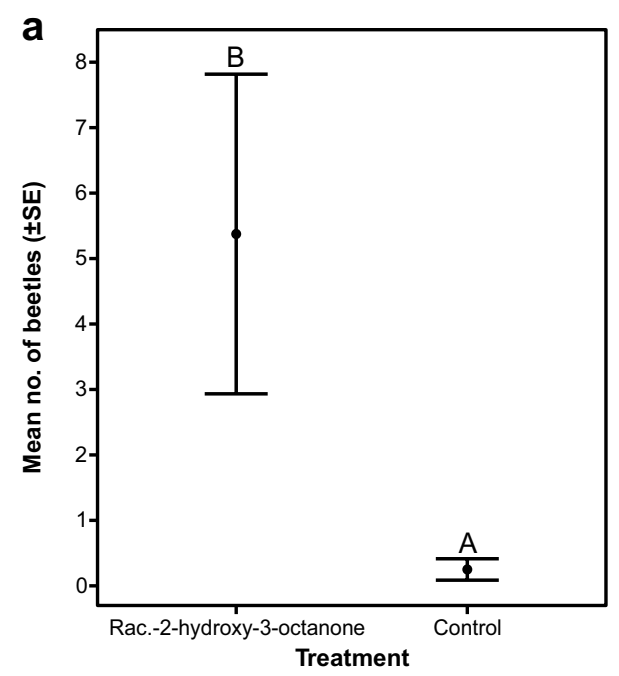

Fig. 4 a Mean $( \pm \mathrm{SE})$ numbers of $X$. antilope captured per trap and sampling period with lures of racemic 2-hydroxy-3-octanone $(50 \mathrm{mg}$ per lure) in $0.5 \mathrm{ml}$ isopropanol ( $n=8$ samples). Controls were baited with $0.5 \mathrm{ml}$ isopropanol alone. Mean values that do not share a common letter are significantly different $(P<0.05)$; b Mean $( \pm \mathrm{SE})$ num-

in our extracts. It is possible that the $(R)$ - and $(S)$-3-hydroxy2-octanone were artefacts generated by thermally induced isomerization of ( $S$ )-2-hydroxy-3-octanone, which is known to occur during GC analysis (Leal et al. 1995). Nevertheless, our bioassays showed that $(S)$-2-hydroxy-3-octanone was attractive as a single component, suggesting that the other components reported by Schröder (1996) are not essential to elicit significant attraction.

Considerable numbers of $X$. antilope had been captured previously in two studies that utilized "multi-lures" consisting of a blend of common cerambycid pheromones including 3-hydroxy-2-hexanone, 3-hydroxy-2-octanone (both racemic) and syn-2,3-hexanediols (Flaherty et al. 2018; Rassati et al. 2018). A direct comparison to our study is not possible, but the blend used by Flaherty et al. (2018) and Rassati et al. (2018) was similar to the blend that we used in parallel to the specific pheromone of $X$. antilope in our 2017 landscape study. As in the studies by Flaherty et al. (2018) and Rassati et al. (2018), we also captured a large number of $X$. antilope with the blend of heterospecific pheromone compounds (total of 162 individuals), but the species-specific pheromone proved significantly more attractive, attracting 7.4 times more beetles (1193 individuals). More importantly, the heterospecific blend failed to detect X. antilope at 14 (26\%) of the 55 sites where the species was captured with its own pheromone (Fig. 5). Cross-attraction to the pheromone components of heterospecifics is common in the subfamily Cerambycinae, and the pheromones of other species could function as cues signaling the location of suitable substrates for species with similar host requirements (Hanks

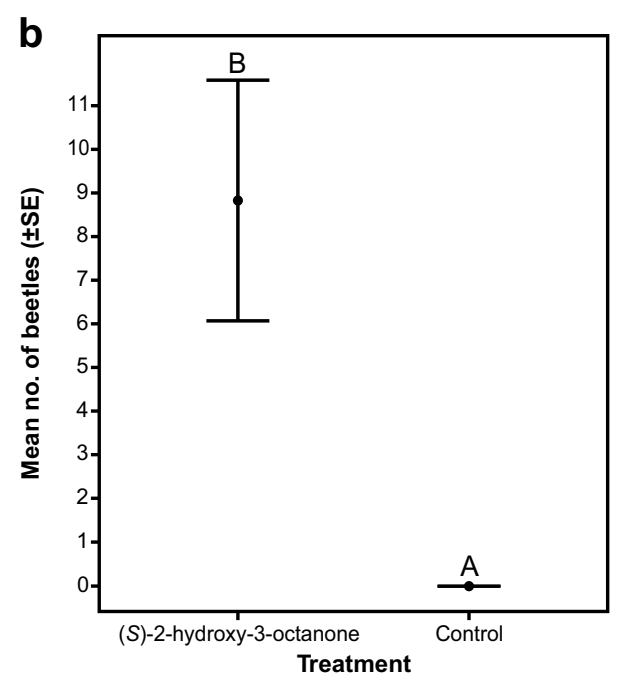

bers of $X$. antilope captured per trap and sampling period with $(S)$ 2-hydroxy-3-octanone ( $25 \mathrm{mg}$ per lure) in $0.5 \mathrm{ml}$ isopropanol $(n=5$ samples). Controls were baited with $0.5 \mathrm{ml}$ isopropanol alone. Mean values that do not share a common letter are significantly different $(P<0.05)$

et al. 2007; Molander and Larsson 2018). However, using the species' specific aggregation-sex pheromone, rather than more generic attractants, can clearly be important to maximize sensitivity during surveys, particularly at low population densities (cf. Svensson et al. 2012). Further, 11 of the 13 sites in the landscape study where no $X$. antilope were captured are situated well outside of the species' current known distribution in Sweden (Fig. 5) (Lindhe et al. 2010; Swedish Species Observation System 2018b). Consequently, traps baited with its own pheromone detected $X$. antilope at $97 \%$ of the surveyed sites that were located within its distribution, and our results extended the species' distribution further south than what was previously known.

With their pheromones identified, A. mysticus and X. antilope can be added to the small but expanding group of rare and threatened cerambycids that can be monitored with aggregation-sex pheromones. Our survey of $X$. antilope at a large number of sites in the landscape study demonstrated a high rate of detection, showing much promise for future studies. Further, the major components of the pheromones of A. mysticus and X. antilope are the same as the two-component aggregation-sex pheromone of Plagionotus detritus ssp. detritus (Linnaeus, 1758), a cerambycid dependent on fresh, coarse oak wood that is highly threatened in parts of Europe (Molander et al. 2019). The fact that compounds are partially shared by multiple rare species of cerambycids is a great advantage because it may be possible to sample multiple target species simultaneously with the same lures and traps, reducing labor and other monitoring costs. However, blends of compounds should first be tested for 


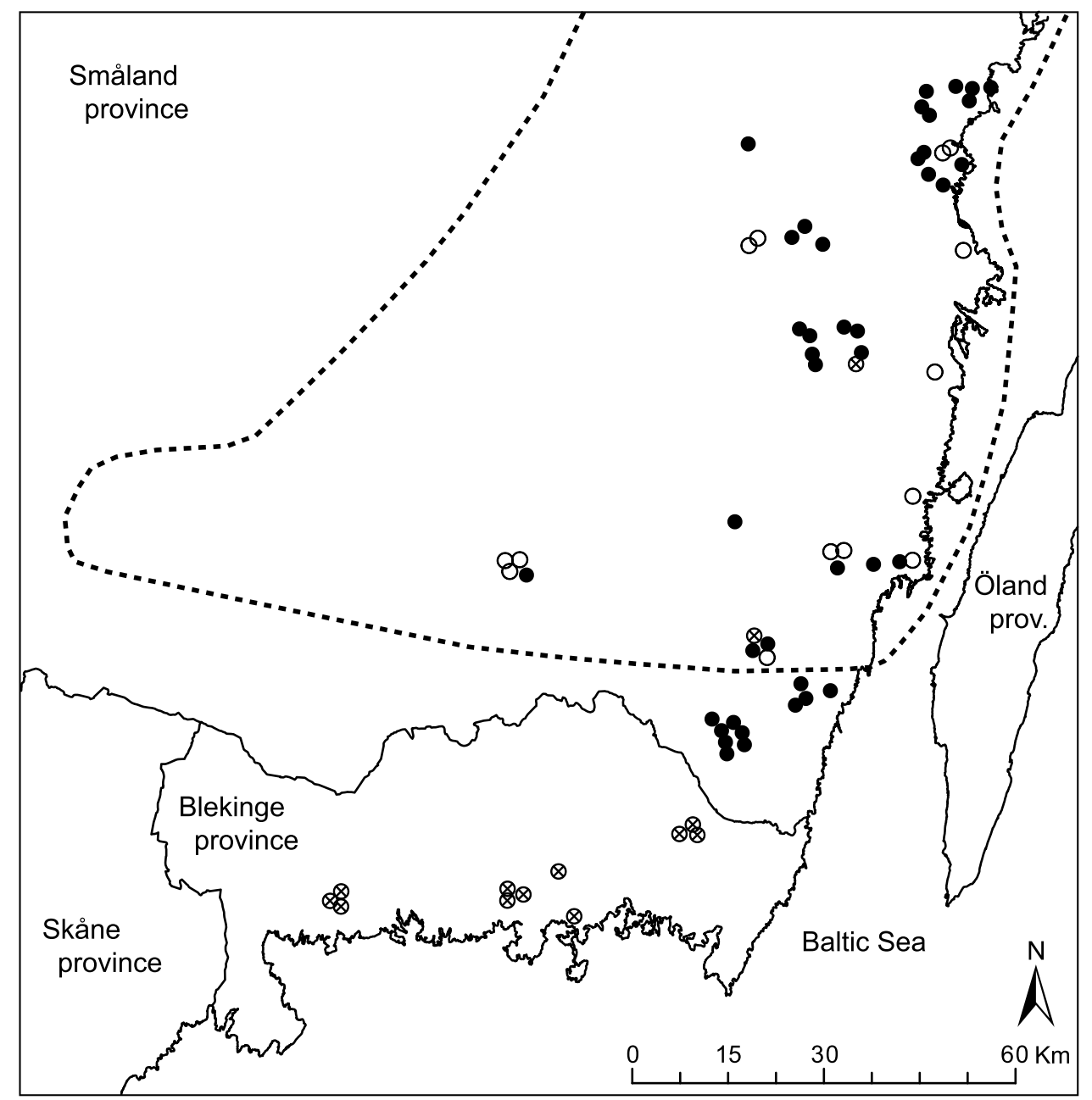

Fig. 5 Map of southeastern Sweden showing the location of 68 sites in a pheromone-based landscape survey of longhorn beetles in 2017, and the approximate southern extent of the distribution of $X$. antilope [hatched line, based on reported records 1700-2016 in Lindhe et al. (2010) and the Swedish Species Observation System (2018b)]. At each site, three traps with the species' specific pheromone (S)-2-hydroxy-3-octanone (25 $\mathrm{mg}$ per lure) were deployed, and three traps with a blend of common heterospecific cerambycid pheromone components as racemates (50 mg 3-hydroxy-2-hexanone,

antagonistic effects among species, because the compounds of one species occasionally can inhibit responses of other species (Millar and Hanks 2017; Hanks et al. 2019). The minor component (2-nonanone) for A. mysticus might be a relatively species-specific compound, at least compared to $(R)$-3-hydroxy-2-hexanone and $(S)$-2-hydroxy-3-octanone, but this component is commercially available at low cost. A portfolio of species with different substrate requirements that can be monitored cost-efficiently with pheromones, could be highly beneficial in designing robust ecological studies that examine, for instance, the effects of different forest management practices on biodiversity. Such studies are needed given the rapid environmental changes that are taking place
$10 \mathrm{mg}$ 3-hydroxy-2-decanone, and $5 \mathrm{mg}$ 3-hydroxy-2-octanone per lure). Filled circles denote sites where the species was detected by traps with both types of pheromone lures, unfilled circles denote sites where the species was detected only by traps with lures of the species' specific pheromone, but not in traps with the heterospecific blend. Circles with a cross denote sites where the species was not captured by any trap. Due to the large scale, the location of certain sites is shown with a minor offset $(<2.0 \mathrm{~km})$ to enhance visibility.

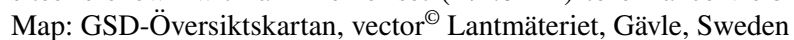

in European forests, such as the intensifying harvest of logging residues (wood substrates) as biofuel, a management practice that removes large quantities of suitable substrates for many longhorn beetles, including the focal species in this study.

Acknowledgements The authors wish to thank Marcus Vestlund, Louise Backström, Adam Nunn, and Simon Jacobsen for assistance with the field and laboratory work. Jonas Helgesson at Helgesson Trädtjänst AB, Stefan Ekroth, Gunnar Isacsson, and the forest companies Stora Enso and Södra Skogsägarna made significant contributions to the supply of oak wood substrates. Göran Birgersson kindly provided support with the GC-MS analyses at the SLU campus. Further, we are grateful to a large number of private landowners and the Royal 
Swedish Academy of Letters, History, and Antiquities for permission to work on their properties. The Swedish forest companies Sveaskog (Per Petersson and Jan Dahl) and Södra Skogsägarna (Therese Lindström and Anders Ekstrand) approved our work within Ecopark Hornsö and assisted in locating suitable trapping sites. Peter Anderson and Fredrik Schlyter offered constructive criticism on an early version of the manuscript. The project was financed by research Grants from the Swedish Environmental Protection Agency (to MCL, Grant: NV-03135-14), the research council Formas (to MCL, Grant: 2016-01372), the Swedish Forest Society Foundation (to MCL, Grants:1011-84/150-7 HJHIL, and 2016-029), Ekfrämjandet; Erik Stenström Foundation (to MCL Grant: 2015-5), WWF Sweden (to MCL, Grant: Insight: SWE 0163; Local: 500 131), the Royal Swedish Academy of Sciences (to MAM, Grant: BS2015-0065), a stipend to MAM from the Entomological Society of Lund (Larsénska fonden), and Grants 14-, 15-, 16-, and 17-8130-1422CA from the United States Department of Agriculture, Animal and Plant Health Inspection Service (USDA-APHIS) to JGM.

\section{Compliance with ethical standards}

Conflict of interest The authors declare that they have no conflict of interest.

Open Access This article is distributed under the terms of the Creative Commons Attribution 4.0 International License (http://creativeco mmons.org/licenses/by/4.0/), which permits unrestricted use, distribution, and reproduction in any medium, provided you give appropriate credit to the original author(s) and the source, provide a link to the Creative Commons license, and indicate if changes were made.

\section{References}

Allison JD, McKenney JL, Millar JG, McElfresh JS, Mitchell RF, Hanks LM (2012) Response of the woodborers Monochamus carolinensis and Monochamus titillator (Coleoptera: Cerambycidae) to known cerambycid pheromones in the presence and absence of the host plant volatile $\alpha$-pinene. Environ Entomol 41:1587-1596. https://doi.org/10.1603/EN12185

Andersson K, Bergman KO, Andersson F, Hedenström E, Jansson N, Burman J, Winde I, Larsson MC, Milberg P (2014) High-accuracy sampling of saproxylic diversity indicators at regional scales with pheromones: the case of Elater ferrugineus (Coleoptera, Elateridae). Biol Conserv 171:156-166. https://doi.org/10.1016/j.bioco n.2014.01.007

Anonymous (2008) Ekoparksplan Hornsö. Sveaskog, Växjö

ArtDatabanken (2015) The 2015 Swedish Red List. Swedish Species Information Centre, Uppsala

Baker TC, Heath JJ (2005) Pheromones: function and use in insect control. In: Gilbert LI, Iatrou K, Gill SS (eds) Comprehensive molecular insect science. Elsevier, Amsterdam, pp 407-459

Barbour JD, Millar JG, Rodstein J, Ray AM, Alston DG, Rejzek M, Dutcher JD, Hanks LM (2011) Synthetic 3,5-dimethyldodecanoic acid serves as a general attractant for multiple species of Prionus (Coleoptera: Cerambycidae). Ann Entomol Soc Am 104:588-593. https://doi.org/10.1603/AN10182

Bates D, Maechler M, Bolker B, Walker S (2015). Fitting linear mixedeffects models using lme4. J Stat Softw 67:1-48. https://doi. org/10.18637/jss.v067.i01

Burman J, Westerberg LW, Ostrow S, Ryrholm N, Bergman K-O, Winde I, Nyabuga FN, Larsson MC, Milberg P (2016) Revealing hidden species distribution with pheromones: the case of
Synanthedon vespiformis (Lepidoptera: Sesiidae) in Sweden. J Insect Conserv 20:11-21. https://doi.org/10.1007/s1084 1-015-9835-9

Cálix M, Alexander KNA, Nieto A, Dodelin B, Soldati F, Telnov D, Vazquez-Albalate X, Aleksandrowicz O, Audisio P, Istrate $\mathrm{P}$, Jansson N, Legakis A, Liberto A, Makris C, Merkl O, Mugerwa Pettersson R, Schlaghamersky J, Bologna MA, Brustel H, Buse J, Novák V, Purchart L (2018) European Red List of saproxylic beetles. IUCN, Brussels

Cardoso P, Erwin TL, Borges PAV, New TR (2011) The seven impediments in invertebrate conservation and how to overcome them. Biol Conserv 144:2647-2655. https://doi.org/10.1016/j.bioco n.2011.07.024

Danilevsky ML (2018) Catalogue of Palaearctic Cerambycoidea. Updated 16.08.2018. https://www.zin.ru/Animalia/Coleoptera/ rus/danlists.htm. Accessed 12 Sep 2018

Diesel NM, Zou Y, Johnson TD, Diesel DA, Millar JG, MongoldDiers JA, Hanks LM (2017) The rare North American cerambycid beetle Dryobius sexnotatus shares a novel pyrrole pheromone component with species in Asia and South America. J Chem Ecol 43:739-744. https://doi.org/10.1007/s 1088 6-017-0875-3

Ehnström B, Axelsson R (2002) Insektsgnag i bark och ved. Swedish Species Information Centre, Uppsala

Ehnström B, Holmer M (2007) Nationalnyckeln till Sveriges flora och fauna. Skalbaggar: Långhorningar. Coleoptera: Cerambycidae. Swedish Species Information Centre, Uppsala

Flaherty L, Gutowski JMG, Hughes C, Mayo P, Mokrzycki T, Pohl G, Silk P, Van Rooyen K, Sweeney J (2018) Pheromone-enhanced lure blends and multiple trap heights improve detection of bark and wood-boring beetles potentially moved in solid wood packaging. J Pest Sci. https://doi.org/10.1007/s10340-018-1019-4

Graham EE, Poland TM (2012) Efficacy of fluon conditioning for capturing cerambycid beetles in different trap designs and persistance on pael traps over time. J Econ Entomol 105:395-401

Hall DR, Cork A, Phythian SJ, Chittamuru S, Jayarama BK, Venkatesha MG, Sreedharan K, Kumar PV, Seetharama HG, Naidu $\mathrm{R}$ (2006) Identification of components of male-produced pheromone of coffee white stemborer, Xylotrechus quadripes. J Chem Ecol 32:195-219. https://doi.org/10.1007/s10886-006-9360-0

Hanks LM, Millar JG (2016) Sex and aggregation-sex pheromones of cerambycid beetles: basic science and practical applications. J Chem Ecol 42:631-654. https://doi.org/10.1007/s1088 6-016-0733-8

Hanks LM, Millar JG, Moreira JA, Barbour JD, Lacey ES, McElfresh JS, Reuter FR, Ray AM (2007) Using generic pheromone lures to expedite identification of aggregation pheromones for the cerambycid beetles Xylotrechus nauticus, Phymatodes lecontei and Neoclytus modestus modestus. J Chem Ecol 33:889-907. https://doi.org/10.1007/s10886-007-9275-4

Hanks LM, Mongold-Diers JA, Mitchell RF, Zou Y, Wong JCH, Meier LR, Johnson TD, Millar JG (2019) The role of minor pheromone components in segregating 14 species of cerambycid beetles of the subfamily Cerambycinae. J Econ Ent (in press)

Hansen (1966) Biller XXII. Træbukke, GEC Gads Forlag, Copenhagen

Harvey DJ, Harvey H, Larsson MC, Svensson GP, Hedenström E, Finch P, Gange AC (2017) Making the invisible visible: determining an accurate national distribution of Elater ferrugineus in the United Kingdom using pheromones. Insect Conserv Diver 10:283-293. https://doi.org/10.1111/icad.12227

Hedin J, Isacsson G, Jonsell M, Komonen A (2008) Forest fuel piles as ecological traps for saproxylic beetles in oak. Scand J For Res 23:348-357. https://doi.org/10.1080/02827580802269991

Hilbe J (2011) Negative binomial regression. Cambridge University Press, Cambridge 
Imrei Z, Millar JG, Tóth M (2013) Field screening of known pheromone components of longhorned beetles in the subfamily Cerambycinae (Coleoptera: Cerambycidae) in Hungary. Zeit für Naturforschung C 68:236-242

Jeppsson T, Lindhe A, Gärdenfors U, Forslund P (2010) The use of historical collections to estimate population trends: a case study using Swedish longhorn beetles (Coleoptera: Cerambycidae). Biol Conserv 143:1940-1950. https://doi.org/10.1016/j.bioco n.2010.04.015

Kadej M, Zając K, Ruta R, Gutowski JM, Tarnawski D, Smolis A, Olbrycht T, Malkiewicz A, Myśków E, Larsson MC, Andersson F, Hedenström E (2015) Sex pheromones as a tool to overcome the Wallacean shortfall in conservation biology: a case of Elater ferrugineus Linneus, 1758 (Coleoptera: Elateridae). J Insect Conserv 19:25-32. https://doi.org/10.1007/s10841-014-9735-4

Klausnitzer B, Klausnitzer U, Wachmann E, Hromádko Z (2016) Die Bockkäfer Mitteleuropas. Die Neue Brehm-Bücherei, Magdeburg

Larsson MC (2016) Pheromones and other semiochemicals for monitoring rare and endangered species. J Chem Ecol 42:853-868. https://doi.org/10.1007/s10886-016-0753-4

Larsson MC, Molander MA (2016) Standardized pheromone-based toolboxes of saproxylic indicator species guiding European conservation efforts? Bulletin de la Société Royale Belge d'Entomologie van de Koninklijke Belgische Vereiniging voor Entomologie 152:157-162

Larsson MC, Svensson GP (2009) Pheromone monitoring of rare and threatened insects: exploiting a pheromone-kairomone system to estimate prey and predator abundance. Cons Biol 23:1516-1525. https://doi.org/10.1111/j.1523-1739.2009.01263.x

Larsson MC, Svensson GP, Ryrholm N (2009) Monitoring rare and threatened insects with pheromone attractants. In: Samways MJ, McGeoch MA, New TR (eds) Insect conservation, a handbook of approaches and methods. Oxford University Press Inc., New York, pp 114-116

Laugsand AE, Olberg S, Reiråskag C (2008) Notes on species of Cerambycinae (Coleoptera) in Norway. Norw J Entomol 55:1-6

Leal WS (2017) Reverse chemical ecology at the service of conservation biology. Proc Natl Acad Sci USA 114:12094-12096. https:// doi.org/10.1073/pnas.1717375114

Leal WS, Shi X, Nakamuta K, Ono M, Meinwald J (1995) Structure, stereochemistry, and thermal isomerization of the male sex pheromone of the longhorn beetle Anaglyptus subfasciatus. Proc Natl Acad Sci USA 92:1038-1042

Lenth R (2018) emmeans: estimated marginal means, aka least-squares means. R package version 1.2.1. https://CRAN.R-project.org/ package $=$ emmeans. Accessed 10 Oct 2018

Lindhe A, Jeppsson T, Ehnström B (2010) Longhorn beetles in Sweden-changes in distribution and abundance over the last two hundred years. Entomologisk Tidskrift 131:241-510

Linsley EG (1959) Ecology of Cerambycidae. Ann Rev Entomol 4:99-138. https://doi.org/10.1146/annurev.en.04.010159.000531

Löfstedt C, Herrebout WM (1988) Sex pheromones of three small ermine moths found on the European spindle tree. Entomol Exp Appl 46:29-38. https://doi.org/10.1111/j.1570-7458.1988.tb022 64.x

McCorquodale DB, Brown JM, Marshall SA (2007) A decline in the number of long-horned wood boring beetle (Coleoptera: Cerambycidae) species in Ontario during the 20th century? J Entomol Soc Ontario 138:107-135

Millar JG, Hanks LM (2017) Chemical ecology of Cerambycids. In: Wang Q (ed) Cerambycidae of the world: biology and pest management. CRC Press/Tayler \& Francis Group, Boca Raton, pp 161-208

Millar JG, Hanks LM, Moreira JA, Barbour JD, Lacey ES (2009) Pheromone chemistry of cerambycid beetles. In: Nakamuta K, Millar
JG (eds) Chemical ecology of wood-boring insects. Forestry and Forest Products Research Institute, Ibaraki, pp 52-79

Mitchell RF, Millar JG, Hanks LM (2013) Blends of (R)-3-hydroxyhexan-2-one and alkan-2-ones identified as potential pheromones produced by three species of cerambycid beetles. Chemoecology 23:121-127. https://doi.org/10.1007/s00049-012-0122-x

Molander MA, Larsson MC (2018) Identification of the aggregationsex pheromone of the cerambycid beetle Phymatodes pusillus ssp. pusillus and evidence of a synergistic effect from a heterospecific pheromone component. J Chem Ecol 44:987-998. https://doi. org/10.1007/s10886-018-1008-3

Molander MA, Helgesson J, Winde IB, Millar JG, Larsson MC (2019) The male-produced aggregation-sex pheromone of the cerambycid beetle Plagionotus detritus ssp. detritus. J Chem Ecol 45:28-36. https://doi.org/10.1007/s10886-018-1031-4

Musa N, Andersson K, Burman J, Andersson F, Hedenström E, Jansson N, Paltto H, Westerberg L, Winde I, Larsson MC, Bergman K-O, Milberg P (2013) Using sex pheromone and a multi-scale approach to predict the distribution of a rare saproxylic beetle. PLoS One 8:e66149. https://doi.org/10.1371/journal.pone.00661 49

Nilsson SG (2001) Sydsveriges viktigaste områden för bevarandet av hotade arter-vedskalbaggar som vägvisare till kärnområdena. Fauna Flora 96:59-70

Nilsson SG, Huggert L (2001) Vedinsektfaunan i Hornsö-Allgunnenområdet i östra Småland. Report 2001:28. Kalmar County Administrative Board, Kalmar

Odegaard F, Olberg S, Hanssen O (2015) Biller (Coleoptera) Norsk rodliste for arter 2015. https://www.artsdatabanken.no/Rodliste/ Artsgruppene/Biller. Accessed 29 Sep 2018

Oleander A, Thackery D, Burman J (2015) The effect of exposure to synthetic pheromone lures on male Zygaena filipendulae mating behaviour: implications for monitoring species of conservation interest. J Insect Conserv 19:539-546. https://doi.org/10.1007/ s10841-015-9775-4

Rassati D, Marini L, Marchioro M, Rapuzzi P, Magnani G, Poloni R, Giovanni FD, Mayo P, Sweeney J (2018) Developing trapping protocols for wood-boring beetles associated with broadleaf trees. J Pest Sci. https://doi.org/10.1007/s10340-018-0984-y

Ray AM, Arnold RA, Swift I, Schapker PA, McCann S, Marshall CJ, McElfresh JS, Millar JG (2014) (R)-Desmolactone is a sex pheromone or sex attractant for the endangered valley elderberry longhorn beetle Desmocerus californicus dimorphus and several congeners (Cerambycidae: Lepturinae). PLoS One 9:e115498. https://doi.org/10.1371/journal.pone.0115498

R Core Team (2018) R: a language and environment for statistical computing. R Foundation for Statistical Computing, Vienna, Austria. https://www.R-project.org/. Accessed 10 Oct 2018

Schröder FC (1996) Identifizierung und Synthese neuer Alkaloide, Hydroxyketone und bicyclischer Acetale aus Insekten. Dissertation, University of Hamburg, Hamburg

Svensson GP, Liedtke C, Hedenström E, Breistein P, Bång J, Larsson MC (2012) Chemical ecology and insect conservation: optimizing pheromone-based monitoring of the threatened saproxylic click beetle Elater ferrugineus. J Insect Conserv 16:549-555. https:// doi.org/10.1007/s10841-011-9440-5

Swedish Species Observation System (2018a) List of records of Anaglyptus mysticus 2000-2016. https://www.artportalen.se/. Accessed 25 Sep 2018

Swedish Species Observation System (2018b) List of records of Xylotrechus antilope 1700-2016. https://www.artportalen.se/. Accessed 1 Dec 2018

Tolasch T, König C, Fragstein MV, Steidle JLM (2013) Identification of the sex pheromone of Idolus picipennis (Bach 1852) revealed the presence of a cryptic sibling species. J Chem Ecol 39:14331440. https://doi.org/10.1007/s10886-013-0360-6 
Witzgall P, Kirsch P, Cork A (2010) Sex pheromones and their impact on pest management. J Chem Ecol 36:80-100. https://doi. org/10.1007/s10886-009-9737-y

Žunič Kosi A, Zou Y, Hoskovec M, Vrezec A, Stritih N, Millar JG (2017) Novel, male-produced aggregation pheromone of the cerambycid beetle Rosalia alpina, a priority species of European conservation concern. PLoS One 12:e0183279. https://doi. org/10.1371/journal.pone.0183279 